\title{
Ciudadanía social y económica como desarrollo. Consideraciones desde el enfoque de Martha Nussbaum
}

\author{
PABLO MARTínEZ BECERRA* \\ Universidad de Playa Ancha (Chile) \\ pablo.martinez@upla.cl
}

\begin{abstract}
Resumen
El enfoque de las capacidades de Martha Nussbaum, como toda concepción humanista, entiende que el desarrollo humano depende de muchos factores que rebasan el componente económico. En el presente artículo se defiende que uno de esos componentes es la ciudadanía que, en sus diversas tipologías, aporta al desenvolvimiento y a los funcionamientos de las personas. Como una teoría de la justicia de corte liberal social, la propuesta de Nussbaum logra incorporar a su estructura argumentativa, una ética del desarrollo que prescribe como deber político el aseguramiento de una base de derechos sociales que sean garantes de la dignidad de las personas, sin que este aseguramiento sea óbice para que se agreguen aquellos derechos sociales y económicos a los que se accede exclusivamente bajo la condición de ciudadano. Por tanto, el artículo sostiene que Nussbaum, como liberal, ha de reconocer el valor que tiene el desenvolvimiento de la vida humana en los ámbitos no políticos, pero, como liberal revisionista y filósofa aristotélica, defenderá que no hay desarrollo sin ciudadanía.
\end{abstract}

Palabras clave: Desarrollo humano, ciudadanía, capacidades, Nussbaum.

\section{Social and economic citizenship as development. Considerations from the approach of Martha Nussbaum}

\begin{abstract}
Martha Nussbaum's capabilities approach, like every bumanist conception, understands that buman development depends on many factors that go beyond the economic component. This article defends that one of these components is citizenship, which, in its various types, contributes to the development and functioning of people. As a theory of social liberal court justice, Nussbaum's proposal manages to incorporate into its argumentative structure, a development ethic that prescribes as a political duty the assurance of a social rights base that guarantees the dignity of people, without that this assurance is an obstacle for those social and economic rights that are accessed exclusively under the condition of citizen to be added. Therefore, the article argues that Nussbaum, as a liberal, must recognize the value of the development of human life in non-political spheres, but, as liberating revisionist and Aristotelian philosopher, he will defend that there is no development without citizenship.
\end{abstract}

Key words: Human development, citizenship, capabilities, Nussbaum.

\footnotetext{
* Doctor en Filosofía, moral y política, por la Universidad de Valencia (España). Licenciado y profesor de Filosofía por la P. Universidad Católica de Valparaíso. Profesor de Ética y Filosofía política de la Universidad de Playa Ancha.

Este trabajo es el resultado de una estancia investigativa en la Universidad de Valencia (Programa "Ética y Democracia"), realizada, durante los meses de enero y febrero de 2019, gracias a la adjudicación de la Beca Santander Iberoamérica. Agradezco el auspicio de la Dra. Adela Cortina y el trabajo tutorial del Dr. Juan Carlos Siurana.
} 
Pretendemos poner de relieve en este artículo, mediante la reflexión crítica, cómo el planteamiento de la filósofa neoyorquina Martha Nussbaum, que constituye una propuesta que entiende la justicia social como dotación de capacidades, enlaza determinados aspectos para concebir una idea de desarrollo más integrativa.

En concordancia con lo anterior, consideramos que de entre las variables que enriquecen la idea del desarrollo presente en el enfoque de Nussbaum —que se suma al ya largo esfuerzo por superar la parcialidad de la idea del desarrollo devenida de la posguerra-, destaca el deber que tienen las naciones de crear capacidades que estén conectadas con el ejercicio de la ciudadanía. Dicho de otro modo, nos importa en este escrito analizar y determinar, desde la propuesta del enfoque de las capacidades, qué valor tiene el fomento y el ejercicio de la "ciudadanía" - entendida como identidad política, posesión de derechos y membrecía-, cuando se trata de trazar los umbrales y los elementos que definen el desarrollo humano.

Toda nuestra indagación se articula desde el presupuesto básico de toda ética del desarrollo, principio que no debe causar saciedad, aunque sea repetido una y otra vez, a saber: el desarrollo no es puramente económico o, para decirlo de otro modo, puede haber crecimiento económico sin desarrollo. Esto significa que constituye un proceso, que al ser evaluado desde una visión poseconomicista como es la de Nussbaum, exige de una concepción de justicia y medidas distributivas que conlleven la promoción tanto de los aspectos individuales-sociales de la vida de las personas como, también, los políticos. Se puede decir entonces que, de entre las complejas variables evaluativas del desarrollo propuestas por el enfoque de las capacidades - en las que figuran el nivel de pobreza, la calidad de la educación, atención sanitaria, etc.-, intentamos discernir cuál es el aporte del ejercicio de la ciudadanía a la "capacidad de ser y hacer de las personas", en el fondo, a la "calidad de vida" propia del desarrollo.

Ahora bien, prestaremos una especial atención y pondremos en un lugar decisivo las implicancias propias de la "ciudadanía social" y de la "ciudadanía económica". A grandes rasgos adelantamos que entendemos la primera como garantía material de la igualdad en el ejercicio de los restantes tipos de ciudadanía y, la segunda, como un contrafáctico ideal de soberanía en el plano de las decisiones económicas que nos afectan. Sin duda, analizar el aporte de la ciudadanía social al desarrollo, nos exige apreciar el valor que los derechos sociales tienen para el ejercicio de los "derechos políticos" y, cuando se trata de hacer lo mismo con la ciudadanía 
económica, hemos de considerar cómo influyen en él los grados de responsabilidad, participación y empoderamiento económico de las personas. Es claro que, finalmente, desde el enfoque de las capacidades, la evaluación del grado de injerencia que ambas ciudadanías tienen en el desarrollo, requiere de considerar cuánto cuenta su posibilidad de ejercicio para la libertad y el florecimiento de las personas. Justamente, porque la concesión formal de un derecho civil o político solo asegura su realidad o ejercicio si, por un lado, se cuenta con la seguridad básica garantizada para todos y si, por otro, existen grados de participación real en las decisiones económicas que nos afectan, es que ponemos en el centro de nuestro análisis a la ciudadanía social y, consecuentemente, a la ciudadanía económica.

Parece evidente que los intentos de apertura de las fronteras de la justicia, es decir, de ampliación de los márgenes de la inclusión en las diversas formas de ciudadanía, junto con atestiguar la mayor densidad de las exigencias estatales respecto de las personas -y otras especies (Martínez, 2015)-, redunda en la extensión e intensificación de la vida humana. Contando con esto, es bien difícil dejar a la ciudadanía en un plano puramente identitario sin que, a la par, se la vincule a la expansión de las potencialidades del ser humano y, por tanto, se la deje fuera de los objetivos del desarrollo.

Para poder dar cuenta de la mutua conexión entre ciudadanía y desarrollo, determinaremos, por un lado, las particularidades del enfoque de las capacidades de Nussbaum y explicaremos qué caracteriza su concepción del desarrollo y, por otro, trazaremos lo que define a cada una de las diversas tipologías de la ciudadanía para establecer cuán gravitantes son para la expansión de las capacidades humanas. En último lugar, determinaremos cómo la base de bienes sociales propios de la "ciudadanía social", equipara las oportunidades de las personas para alcanzar los modos de vida que valoran y, a la vez, la manera en que el empoderamiento económico propio de la "ciudadanía económica" se yergue como una forma fundamental de autonomía.

\section{Algunos anteCeDENTES DE LA ÉTICA DEL DESARROLlO CENTRADA EN LAS CAPACIDADES}

La propuesta del enfoque de las capacidades, al menos en la versión de Nussbaum y de Sen, plantea su ética del desarrollo desde una perspectiva adscrita al liberalismo político y, por lo tanto, desde una "teoría de la justicia" particular.

Sin embargo, este enfoque liberal cuando se trata de asegurar la justicia social no sitúa el centro en los bienes básicos, sino en la "capacidad de ser 
y hacer que tiene cada persona" y, en este sentido, su objeto es crear una base de capacidades que permitan generar oportunidades y, a la par, opciones de elección para las personas. Por ser un enfoque político, establece cuál ha de ser el mínimo de capacidades que debe cautelar el "Estado y las políticas públicas" como un derecho universal para todas las personas (Nussbaum, 2012: 39). En razón de ello, no se trata de determinar conductas desde el Estado, pero sí de posibilitar, desde él, que las personas funcionen en los ámbitos existenciales que valoran. Ciertamente, si los gobiernos fomentasen los funcionamientos y no las capacidades, estarían incorporando elementos definidos que pertenecen a las doctrinas compresivas y, por lo tanto, sentarían prescripciones desde una perspectiva moral que se volvería contraria al pluralismo.

Al entender de Nussbaum, el orden político tiene la obligación de proveer las capacidades mínimas que permitan a las personas vivir una vida a la altura de su dignidad. Así concebidas, no es extraño que parte de las capacidades se identifique con los derechos fundamentales del individuo. Añadamos que el enfoque entiende que las capacidades mínimas, que configuran mayormente una base de derechos sociales, son fértiles en el ejercicio de las diversas formas de ciudadanía, pero, también, son fundamentales para tener la posibilidad de llevar una vida, de funcionar, conforme a las propias valoraciones y a la libertad de conciencia propia de cada persona. Dicho de otro modo, la justicia social desde el enfoque de las capacidades configura las "precondiciones", no sólo para ser "ciudadano", sino, también, para, virtualmente, ser plenamente "hombre" (varón/mujer) en relación con el proyecto de vida elegido por cada persona. Por ello, el enfoque sostiene que "lo justo y lo bueno parecen estar completamente interrelacionados" (Nussbaum, 2007: 169). Luego, la propuesta de Nussbaum, excluyéndose de ser una doctrina compresiva, puede tanto ser, directamente, una teoría de la justicia como, indirectamente, una teoría de la plenitud humana (florecimiento). En última instancia, las capacidades mínimas prescritas a nivel político son garantía de igualdad y posibilitan los funcionamientos que son manifestación de la deliberación y elección humana, no sólo a nivel político, sino al nivel individual y social.

Ahora bien, la idea del desarrollo actual, se la entiende devenida de un proceso que comienza con las críticas al "enfoque del crecimiento", pasa por el revisionismo del "enfoque de las necesidades", y se perfecciona en el "enfoque centrado en las personas". Justamente este último, es coincidente con la propuesta de las capacidades de Amartya Sen y Martha Nussbaum (Goldin, 2016).

Sin duda, centrarse en las personas como lo hace Nussbaum, involucra asumir que el desarrollo no se reduce al alza del PIB o al grado de 
industrialización, sino que ha de ser evaluado desde un baremo más complejo en el cual son determinantes los niveles de justicia social en relación con la creación de capacidades y el bienestar. Una perspectiva humanista como ésta, continúa los planteamientos de los fundadores de la ética del desarrollo. Tengamos presente la siguiente afirmación de Goulet, uno de los pioneros:

Aunque el desarrollo puede ser estudiado con provecho como un fenómeno económico, político, tecnológico o social, sin embargo, sus fines últimos son los de la existencia misma: proporcionar a todos los seres humanos la oportunidad de vivir con plenitud una vida humana. (Goulet, 1999: 27)

Desde luego, el arraigo del enfoque de las capacidades a la teoría económica y sus repercusiones efectivas en los procesos evaluativos del desarrollo de las instituciones financieras y políticas (Banco Mundial, Oficina del Informe sobre el Desarrollo humano de la ONU, etc.), parece mostrar que se mueve por el carril del discurso económico y cuando se despliega sobre la base del discurso filosófico, lo hace con un fin transformador endógeno y empleándolo como garante de la razonabilidad de las propuestas. De esta suerte, parece que mientras algunas éticas del desarrollo surgen allegadas a una corriente filosófico-religiosa, la idea del desarrollo del enfoque de las capacidades parece una "contrateoría" ética que intenta corregir el liberalismo vigente desde la crítica directa a la "economía del desarrollo" imperante y mediante una influencia directa en los "diseñadores de políticas" (Nussbaum, 2012: 16). Por tanto, viene a morigerar y transformar el capitalismo desde sus coordenadas económicas más íntimas y desde los protagonistas del mismo. Así, por ejemplo, el centro no es sólo criticar la ausencia de justicia social, sino aventurar modos concretos de medir la calidad de vida evidenciando la insuficiencia de hacerlo solo calculando el producto interior bruto (PIB). Es manifiesto que el enfoque de las capacidades acoge la filosofía (Sen) y es defendido por una filósofa (Nussbaum), pero su centro es comprometer y poner al servicio de la vida de las personas, las políticas públicas y la transformación progresiva de las instituciones económicas y financieras, proporcionando, al menos en el caso de Nussbaum, un "catálogo diferente de prioridades y una manera de ordenarlas" (Nussbaum, 2012: 16). Por ello, es la misma filósofa quien expresa que el enfoque de las capacidades se alza como "un nuevo paradigma teórico en el campo del desarrollo y las políticas públicas" (Nussbaum, 2012: 14). 
2. LO QUE CUENTA PARA LA EVALUACIÓN DEL DESARROLLO: FLORECIMIENTO Y LIBERTAD

Por lo mismo que el centro del desarrollo en el enfoque de Nussbaum son las personas, es que dicho desarrollo debe ser evaluado desde una medida que se haga cargo de lo que significa la expansión y el florecimiento personal y no sólo desde la variable del crecimiento económico. En un sentido no muy distinto se expresa Goulet, tanto en relación con el "desarrollo en cuando pensado" como respecto del "desarrollo en cuanto vivido", cuando sostiene:

La disciplina del desarrollo es el estudio de las vías para conseguir una economía más humana. [...] Las sociedades son más humanas o más desarrolladas, no cuando los hombres y mujeres "tienen más, sino cuando son capaces de "ser más". El criterio principal de desarrollo no es el incremento de la producción ni del bienestar material, sino el enriquecimiento humano cualitativo. (Goulet, 1999: 27)

Por su parte Nussbaum, defiende que la finalidad del desarrollo es que "las personas vivan vidas plenas y creativas, desarrollen su potencial y formen una existencia significativa acorde con la igualdad de dignidad humana de todos los individuos" (Nussbaum, 2012: 217). El enfoque de la profesora de Chicago articula desde las "capacidades y funcionamientos valiosos", que actúan como ejes de otros elementos indispensables, los bienes primarios con la no dominación, la libertad positiva con la negativa, las necesidades básicas con la vida plena, la autonomía y los derechos, etc. Por ello, desde la perspectiva de la fundamentación filosófica, no extraña que el enfoque de Nussbaum logre aquello que Crocker entiende como una alternativa viable para relacionar los aspectos morales y sociales del desarrollo con los de índole política, es decir, "un concepto de bienestar humano que combina, de un lado, un compromiso neo-kantiano hacia la autonomía, el diálogo crítico y la deliberación pública, y, del otro, creencias neo-aristotélicas sobre la importancia de la salud física y la participación social. Los deberes del desarrollo humano deben fluir desde la idea de que todos los humanos deben tener el derecho, al menos, de un mínimo nivel de bienestar" (Crocker, 2003: 83).

El enfoque de las capacidades en la versión de Nussbaum, determina un mínimo de capacidades a desarrollar que cumple suficientemente con las exigencias de justicia social y transforma el sentido de la justicia distributiva. Indudablemente, el cumplimiento de las prescripciones para la creación de las capacidades mínimas para todos, requiere del crecimiento económico y, por supuesto, de una "estructura política básica de la nación" 
capaz de hacerse "responsable de distribuir una cantidad adecuada (superior a un umbral mínimo) de todos los derechos entre los ciudadanos y ciudadanas" (Nussbaum, 2012: 85). Sin embargo, Nussbaum es consciente del valor subordinado del crecimiento económico, a tal punto que muestra que hay ocasiones en que se vuelve indeseable. Por ejemplo, cuando las inversiones suponen un riesgo para las formas de vida de cierto grupo, llegado el caso la filósofa afirma:

Seguramente, cuando la pobreza adquiere un rostro humano, surgen dudas y vacilaciones sobre la búsqueda del crecimiento, pues para atraer las inversiones extranjeras con frecuencia se necesitan políticas que representan una clara desventaja para los sectores más pobres de la población rural. En muchas partes de la India, por ejemplo, los trabajadores agrícolas conservan tierras que se necesitan para la construcción de fabricas, y en general no salen ganando cuando el gobierno confisca esas tierras, ya que si bien se los indemniza, carecen de la capacitación necesaria para ser empleados por las nuevas industrias que los desplazan. (Nussbaum, 2010: 45)

El foco de las objeciones contra el desarrollo económico sin más, se centra en mostrar que éste no se trata simplemente de un "crezco y, a continuación, distribuyo", sino que, todo enfoque centrado en las personas, exige considerar otros aspectos relacionados con el bienestar y las valoraciones respecto a cómo se quiere vivir, tanto individual como colectivamente. En otras palabras, el desarrollo no es, como han pensado Chenery, Jolly y Ahluwalia, "la redistribución a partir del crecimiento" (Goldin, 2016: 8), pues eso sería caer en una premisa propia del desarrollismo que defiende la concomitancia y proporcionalidad perfecta de las variables económicas respecto a las no-económicas o, simplemente, la prioridad de las primeras. En referencia a ello, Martínez Navarro ha sido enfático: "En muchos casos es posible que se produzca un avance en el desarrollo de una sociedad sin necesidad de que esa sociedad tenga que crecer económicamente" (Martínez, 2000: 51). Además, la crisis ecológica exige el dominio de la "violencia estratégica" que se ejerce cuando el sistema capitalista se mueve solo por el principio de maximización de utilidades, por la disminución de los costes, y, cuando, por diversos medios socava los aspectos éticos del consumo.

Sentado lo anterior, es pertinente decir que, así como Nussbaum señala que las empresas, las organizaciones y los gobiernos tienen responsabilidad con el desarrollo, también lo tienen los individuos que son su sujeto, pues, decir que el sentido del desarrollo son las personas no significa que deban recibirlo pasivamente, sino, antes bien, que ellas han de coactuar para su fomento. Para decirlo de otro modo, el desarrollo, al igual que 
la ciudadanía, ha de poseer un status legal, en cuanto que las personas tienen "derecho al desarrollo" y un status moral en cuanto han de asumir un "conjunto de responsabilidades" (Cortina, 2009: 151). Como veremos, la ciudadanía, cuando es activa, ofrece elementos imprescindibles para cooperar al desarrollo a la vez que el desarrollo mismo es condición de expansión y realización del ser humano.

Los informes de la Naciones Unidas sobre el Desarrollo Humano, han manifestado claramente el plexo que implica el desarrollo y cómo éste integra elementos económicos sociales y políticos. A la par, han puesto de relieve cuáles son los rasgos propios del crecimiento distorsionado o el mal desarrollo, logrando así mostrar qué se ha de evitar si queremos promover el desarrollo de las personas concretas. Ian Goldin ilustra el contenido de un informe significativo respecto al mal desarrollo o crecimiento distorsionado, dice:

El informe de 1996 identificó cinco tipos de crecimiento distorsionado: crecimiento sin empleo, crecimiento sin equidad (solo un pequeño grupo se beneficia), crecimiento sin voz de las comunidades (sin democracia y sin poder, especialmente por parte de las mujeres), crecimiento sin raíces (la identidad cultural está desaparecida) y crecimiento sin futuro (no se conservan los recursos y el medioambiente para las futuras generaciones). (Goldin, 2016: 9-10)

Es manifiesto que el Informe no deja de poner énfasis en los aspectos políticos faltantes al desarrollo, por ello, sea entendido éste como libertad o como florecimiento, ha de requerir de instituciones democráticas sólidas, de una razón pública ejercitada y, sin duda, de ciudadanos empoderados capaces de demandar los cambios sociales adecuados. Acontece entonces que "la ciudadanía plena e igualitaria", al entender de Nussbaum, no es un apéndice insignificante para la vida de las personas, sino una forma de realización propia que responde al hecho de ser animales sociales y, por lo mismo, no se puede dudar que la inserción de pleno derecho en la comunidad política es fundamental para el desarrollo humano (Nussbaum, 2007: 103). La ciudadanía responde a ciertas capacidades que pueden desplegar los seres humanos y, por tanto, no se puede dudar que su promoción sea un deber. Con arreglo a ello, es coherente que Nussbaum considere entre las diez capacidades que propone, que son la base de la justicia social, la "razón práctica" y, de algún modo, el "empoderamiento político" (Nussbaum, 2007: 54-55).

Con todo, consideramos que, para hacer visible de mejor manera el modo en que se vincula esa dotación universal de funcionamientos pro- 
pios de la ciudadanía con una concepción compleja del desarrollo, se justifica que distingamos, primeramente, parte de los tipos de ciudadanía devenidas de una larga búsqueda de reconocimiento y, luego, conectemos los derechos sociales y económicos con la realización de la ciudadanía política.

3. MODOS DE CIUDADANÍA, DERECHOS POLÍTICOS, SOCIALES Y ECONÓMI$\cos$

Antes de abundar en el aporte de la ciudadanía a los funcionamientos y libertades humanas y, por tanto, al desarrollo, resulta apropiado hacer dos advertencias importantes. Por un lado, que el comprensible entusiasmo por los efectos identitarios de la ciudadanía, no debe obnubilar la mirada respecto del valor de ciertos ámbitos no políticos en los que, también, se genera identidad y pertenencia y, por otro, que se debe tener presente que los derechos no son sólo "derechos ciudadanos", sino, también, de las "personas". En lo que a esto último se refiere, hay señalar que muchos derechos incluidos como parte de los derechos sociales, no son dependientes de la condición de ciudadano, sino de la universalidad de la dignidad reconocida al ser humano (Ferrajoli, 2001: 99). Esto se ve claro en algunas naciones en las que, conjugándose el resguardo de los derechos con el aseguramiento de altos grados de inclusión,

la mayoría de los inmigrantes ya disfrutan de un estado de residencia seguro y amplios derechos económicos y sociales que difieren solo en los márgenes de aquellos de los ciudadanos. La ciudadanía agregaría una protección completa contra la expulsión, el acceso al empleo en el sector público y la elegibilidad para aquellos pocos servicios sociales y beneficios que se limitan a los ciudadanos. (Brubaker, 1992: 181)

En este sentido, afirma Ferrajoli que "los derechos sociales pueden ser, y habitualmente son, en parte de la persona y en parte del ciudadano" (Ferrajoli, 2001: 99). Conforme a ello, se entienden las críticas hechas a Marshall, cuando hace depender del estatus de ciudadano el reconocimiento de una serie de derechos que ya están sancionados como tales para las personas.

Sin embargo, los juicios anteriores no pueden llevarnos a considerar superflua la condición de ciudadano, sino, más bien, a valorizar que algunas naciones respeten la dimensión de los derechos sociales sin necesidad de que la persona tenga un vínculo legal con su Estado. Pero, debemos ser cautos, pues, si bien reconocer parte de los derechos sociales a los que no son ciudadanos es muestra de respeto a la dignidad humana, también esta 
concesión puede transformarse en una medida estratégica que permite mantener la exclusión política acallando las aspiraciones por medio de la satisfacción de un mínimo de necesidades. Por lo demás, no debemos olvidar la situación en que se encuentran los indocumentados, los "ilegales", que tras duros procesos migratorios, tienen que sufrir la "muerte civil y el silenciamiento político", ni tampoco a los "residentes permanentes legales" para los que la falta de la "voz política" que confiere la ciudadanía les lleva a una "efectiva alienación" (Benhabid, 2005: 153).

Para estimar el valor particular de la ciudadanía, tengamos en cuenta que los ciudadanos, por ejemplo, están obligados a respetar los derechos humanos fundamentales de inmigrantes, residentes y turistas, pero, en ningún caso están exigidos, como nos dice Donaldson y Kymlicka, a que sus "ciudades sean más acogedoras para los visitantes y son los ciudadanos, no son los visitantes, quienes toman esa decisión colectiva sobre la forma de su sociedad y su espacio público" (Donaldson-Kymlicka, 2018: 99). Agreguemos, que los "visitantes [y los no-ciudadanos en general] no votan en las elecciones ni referéndums que determinan las políticas sobre la señalización de las calles" (Donaldson-Kymlicka, 2018: 100). Por ello, pese a la serie de derechos de los cuales puede participar un no-ciudadano, queda en evidencia, por un parte, que sus intereses no pesan igual que los de aquellos que sí lo son (Donaldson-Kymlicka, 2018: 100) y, por otra, que al carecer de la pertenencia plena a la comunidad política, la persona pierde una preciada esfera de acción en la que desenvolver su actividad vital.

Supuesto, entonces, que hay derechos humanos que tienden a verse traslapados con los de ciudadanía, es pertinente adentrarnos en las modalidades que esta última detenta.

Las distinciones que se pueden hacer de los modos de ciudadanía son diversas y tienden a multiplicarse. Al entender de Ferrajoli, la explosiva diversificación de los derechos, y sus correspondientes "ciudadanías", se genera a instancias de darle un estatus cuasi jurídico a "cualquier expectativa merecedora de tutela" (Ferrajoli, 2001: 106). En nuestro caso, nos ceñiremos al listado de ciudadanías analizadas por Marshall, sumándole sólo la "ciudadanía económica", no tanto por autolimitarnos haciendo caso irrestricto al realismo del derecho positivo, ya que en caso alguno pretendemos renunciar a las expectativas y a la aspiración al deber ser propio de las teorías de la justicia, sino para contar con aquellas que son imprescindibles y que simplifican nuestro análisis en relación al desarrollo. En otras palabras, nos restringiremos a las dimensiones civil, política, social y económica de la ciudadanía. Por lo demás, atendemos a la dificultad para caracterizarla dentro de un contexto de discusión en el que republicanos, comunitaristas, libertarios, liberales, entre otros, disputan en torno a la 
preponderancia de la misma y a la conceptualización más apropiada (Cortina, 2001: 138). A su vez, acotar el análisis se justifica atendiendo a que el proceso de globalización ha diversificado las ciudadanías hasta vernos exigidos a usar una serie de adjetivaciones como: "flexible", "desagregada", "múltiple", "posnacional", etc. Tal gama de derivaciones necesita un tratamiento específico que aquí no le podemos dar.

Entonces, tomando en cuenta lo anterior, podemos distinguir sucintamente:

1) Ciudadanía civil, que se expresa en el ejercicio de "derechos civiles" que son, según expone Held, los "necesarios para asegurar la autonomía individual, que incluye la libertad personal, la libertad de palabra, pensamiento y creencias, el derecho de propiedad y de suscribir contratos, y la igualdad ante la ley" (Held, 1997: 91). De acuerdo con Marshall, el surgimiento de estos derechos se daría en el siglo XVIII. Adela Cortina, por su parte, señala que esta dimensión diferenciada de la ciudadanía se ejerce en cuanto "miembro de la sociedad civil", en otras palabras, en cuanto se pertenece a "un conjunto de asociaciones no políticas ni económicas, esenciales para su socialización y para el cotidiano desarrollo de su vida" (Cortina, 2009: 116). Es decir, así como se es miembro de la sociedad política (Estado), también se es miembro de una sociedad civil en la que hay diversas asociaciones "cívicas" que hay que fomentar por perseguir fines beneficiosos para la sociedad y, sin duda, "anticívicas" que hay que superar en la medida en que socavan o dañan la cohesión social. Evidentemente, el considerar y, a la vez, reforzar una ciudadanía civil no se orienta a la prescindencia del Estado y al imperio del mercado, sino a una sociedad civil vigorosa que suscite, entre otras cosas, hábitos de ciudadanía. Es decir, desde este ámbito en principio ajeno a lo político, en cuanto esfera de la civilitas (civilidad, moral) y no de la civitas (comunidad política), se pueden formar, no obstante, las virtudes o disposiciones para la solidaridad que son vitales en las distintas ciudadanías. Sublimar y morigerar el deseo, es una tarea que se lleva a cabo principalmente en las redes de la sociedad civil, pues, como dice Ulrich:

Con puros egoístas, que solo ven en la política una continuación de los negocios privados por otros medios y que lo único que hace con ella es maximizar su propia ventaja y sus intereses particulares, no es posible, literalmente, constituir "ningún Estado" y mucho menos ningún orden supranacional. (Ulrich, 2006: 49)

2) Ciudadanía política que supone la adquisición de "derechos políticos" que, al decir de Held, "se refieren a aquellos tipos de derechos que crean 
la posibilidad de participar en el ejercicio del poder político como miembro de la asociación política, o como elector de los miembros de la asociación" (Held, 1997: 92). De acuerdo con Marshall estos derechos son conquistados en siglo XIX. Sin duda desde esta ciudadanía se configura la "identidad pública" por medio de la participación, vía directa o por representación, en el gobierno o en la legislación. Si bien desde la visión genética ideada por Marshall, primero es la ciudanía social, en cuanto a la definición misma, primero es la ciudadanía política, en la medida en que "la ciudadanía es primariamente una relación política, en virtud de la cual el individuo es miembro de pleno derecho de esa comunidad [...]" (Cortina, 2009: 35).

3) Ciudadanía social que, con sus diversos altibajos, sigue siendo defendida como un ideal irrenunciable de toda ciudadanía que se precie de plena, implica "medidas redistributivas de bienestar — que incluyen las medidas que fundan la seguridad social, la salud pública y nuevas formas de tributación progresiva_-" (Held, 1997: 93). A juicio de Marshall, estos beneficios se reconocen como derechos en el siglo XX. Indudablemente, después de la crisis del "Estado de bienestar" se los entiende adscritos al "Estado social de derecho" y conectados a la posibilidad de ejercer una "ciudadanía activa". La ciudadanía social junto con generar resguardo respecto del abuso del poder político, puede ser el puntal de la búsqueda tanto de una contrafactual "igualdad de oportunidades" como de una real, y más modesta, "oportunidades decentes para todos" (Sunstein, 2018: 196). Los derechos sociales, sabiendo que no todos ellos pertenecen al ciudadano, previenen del infortunio, pero, sobre todo velan por mantener una vida digna para los que se les ha resistido la fortuna.

4) Ciudadanía económica que suma a la ciudadanía social, el empoderamiento respecto de los bienes sociales y la participación en las decisiones económicas en condiciones de simetría como ideal contrafáctico (Cortina, 2009: 151). Desde luego, la ciudadanía económica concuerda más con un Estado social que esté orientado al despliegue de capacidades y, por tanto, preocupado de las libertades, que con un Estado asistencialista. Ciertamente, en la evolución del capitalismo actual, marcada sustancialmente por la globalización, una ciudadanía adjetivada como "económica" parece, precisamente, una contradicción en los términos, pues, sin necesidad de analizar mucho, la economía se muestra venciendo a la política (Conill, 2001: 246). Sin embargo, esta aparente bancarrota de la política frente a la economía interconectada por redes supranacionales, se alza como la motivación esencial para que la "ciudadanía económica" sea imprescindible como el momento deliberativo faltante en los procesos económicos que afectan a las personas. Así, por ejemplo, sólo la ciudadanía económica implica las 
disposiciones para ejercer el control político sobre el capital que permita revertir la desigualdad a escala nacional y global (Jongitud, 2017). Esta tipología de la ciudadanía se enarbola como garantía de deliberación y participación en las decisiones relativas a las distintas dimensiones del capital. Es decir, implica el control democrático no sólo del capital industrial o económico, sino del financiero y "cognitivo" (Cubillos, Slachevsky \& Yáñez, 2019). Ulrich define en los siguientes términos al "ciudadano económico":

El concepto del ciudadano económico [...] tematiza al ciudadano como persona moral y sujeto económico, que está interesado en la legitimidad de su propio quehacer económico como en el de los otros sujetos económicos y posee para esta autocomprensión una correspondiente virtud civil económica. (Ulrich, 2008: 245)

Evidentemente, la ciudadanía económica es independiente del "éxito" o "fracaso" económico de las personas, dado que se vincula, más bien, con el hecho de estar formado para deliberar en torno a las normas y a las decisiones del plano económico y, por lo mismo, capacitado para autodeterminarse (Ulrich, 2008).

Estas facetas de la ciudadanía representan modos de actuación de las personas que va desde la pertenencia a una "nacionalidad" al menos, pasa por el ejercicio de la "soberanía" popular que legitima al Estado, y llega a la "agencia política democrática" que se manifiesta en la coautoría de las leyes y en la injerencia activa en el proceso democrático (Donaldson \& Kymlicka, 2018: 105-109).

\section{EJERCICIO CIUDADANO Y DESARROLLO}

Martha Nussbaum considera que la capacitación mínima es un derecho de los seres humanos no por ser miembros de una comunidad política, sino por el sólo hecho de ser personas. Las capacidades básicas son entonces disposiciones que, al entender de la filósofa, han de poseer el carácter de universalidad e incondicionalidad propia de los derechos humanos (Nussbaum, 2012: 199). En otras palabras, la justicia social, para Nussbaum, vendría a ser en parte prepolítica, supranacional, universal e incondicionada, por lo que, conforme a ello, el enfoque de las capacidades se plantea como "una teoría de los derechos básicos de los seres humanos" (Nussbaum, 2007: 83). 


\subsection{Ciudadanía y resguardo económico-social}

Con arreglo a lo anterior, si la teoría de la justicia planteada por Nussbaum establece exigencias al Estado que, primariamente, guardan relación con el estatus de persona, cabe preguntarse por el valor accesorio que en su enfoque podría tener la ciudadanía, es decir, si ésta no parece ser requisito para ser sujeto de derechos y capacidades, su valor queda bastante relativizado.

Sin embargo, es la misma lista de capacidades mínimas universales destinadas a todas las personas sin exclusión, la que prescribe, como deber de justicia e indicio de desarrollo, el desenvolvimiento de funcionamientos en el plano político o ciudadano. Para Nussbaum, entonces, la misma justicia social y el desarrollo (humano) no puede prescindir de que a todas las personas les quepa acceder a tener un vínculo, en condiciones de igualdad, con el poder público y a contar con derechos y deberes políticos, y la razón fundamental reside en que funcionar como ciudadano es parte del sentido que tiene la dotación de capacidades. Dicho de otro modo, la vida plena del ser humano implica desplegar, como de alguna manera ya se ha expresado, su condición de "ciudadano" (política) a la vez que su dimensión de "hombre" (moral), o sea, requiere, primero, de ciertos derechos, segundo, de acceso a la participación y, tercero, de configurar una identidad que genere el sentimiento de pertenencia. Aún más, el ejercicio de la ciudadanía, como ha destacado Sen, posee un valor por sí mismo para la vida humana, dice el economista: "La participación política y social tiene un valor intrínseco para la vida y el bienestar de los hombres. Evitar la participación en la vida política constituye una privación mayor" (Sen, 2006: 73).

Sin duda, el ser ciudadano como condición de pertenencia legal a una nación, o al nivel supranacional, redunda en nuevas posibilidades de funcionamientos que derivan de los espacios que se abren para ejercer las capacidades. Esto significa que la ciudadanía forma parte de lo que puede ser y hacer la persona y, en esa medida, es indicio de desarrollo humano. Según parece, los derechos del ciudadano, para Nussbaum, junto a los derechos de la persona, como hemos sostenido, tienen su lugar en la consecución del florecimiento. Además, Sen ha puesto de relieve que la práctica ciudadana de las libertades políticas tiene un valor endógeno respecto del desarrollo cuando expresa:

Aun cuando se ha planteado con frecuencia la cuestión de si la libertad política es "conducente al desarrollo", no debemos omitir el reconocimiento crucial de que las libertades políticas y derechos democráticos están entre los "componentes constitutivos" del desarrollo. Su relevancia para el desarrollo 
no tiene que ser establecida indirectamente a través de su contribución al crecimiento del producto nacional bruto. (Sen, 2010: 378)

Conforme a lo dicho, la justicia social que implica la dotación de capacidades mínimas está constituida, para Nussbaum y Sen, tanto de derechos fundamentales, como de los derechos sociales propios de la ciudadanía social cuyo goce se conecta con los umbrales marcados por la dignidad de la persona. Como ya se ha indicado de algún modo, por ser un asunto de derechos para todos, "los proponentes de la ética de las capacidades defienden la responsabilidad gubernamental en capacitar a cada uno para avanzar hacia un nivel de suficiencia con respecto a los funcionamientos valiosos" (Crocker, 2003: 83).

Ahora bien, la posesión de la ciudadanía social la entiende Nussbaum orientada hacia el ejercicio de los derechos civiles, pero, a su vez, a la realización de la ciudadanía política. En otras palabras, el enfoque de la profesora de Chicago, no se limita a buscar el goce de los derechos sociales, pues, "usa la lista de diez capacidades centrales como una base para la idea de unos derechos políticos fundamentales contemplados en el derecho constitucional" (Nussbaum, 2012: 92). Los derechos sociales propios de la ciudadanía social son la condición necesaria para que, sobre todo los más desfavorecidos, tengan la posibilidad de ejercer los derechos políticos. Es más, para Nussbaum, los derechos políticos no se garantizan con su exclusiva promulgación, sino que requieren de una implementación en la cual es esencial la base económica mínima de los derechos sociales.

De lo anterior se sigue que en el enfoque de las capacidades se considera que reconocer un derecho debe ir unido a la capacidad efectiva que tienen los ciudadanos de ejercerlos (Nussbaum, 2007: 285). Precisamente, al evaluar la justicia social en términos de capacidades, se evita el verdadero vicio que tienen los estados de reconocer derechos políticos y civiles sin las medidas que permiten su ejercicio. De acuerdo a lo expresado, cuando la autora neoyorquina pregunta si «pueden garantizarse las libertades políticas y civiles antes e independientemente del reconocimiento de los derechos sociales y económicos» (Nussbaum, 2007: 286), su respuesta es taxativamente negativa. Evidentemente, es casi imposible que quien está preocupado de la supervivencia, pueda, empoderarse en el plano de los derechos civiles y políticos (Nussbaum, 2007: 286). Dice la filósofa:

El enfoque de las capacidades insiste en los aspectos materiales de los bienes humanos, al dirigir nuestra atención hacia lo que las personas son realmente capaces de ser y hacer. Todas las libertades básicas se definen como capacidades para hacer algo. No pueden considerarse garantizadas si las privacio- 
nes económicas o educativas hacen que las personas sean incapaces de actuar realmente de acuerdo con las libertades que se reconocen sobre el papel. De este modo, el enfoque subraya la interdependencia entre las libertades y el orden económico. (Nussbaum, 2007: 288)

La conexión no es difícil de aceptar y está abalada por los argumentos, por poner un ejemplo, de toda la tradición republicana. El republicanismo, pensemos en el propietarista, aboga por una libertad que está solventada en las opciones de elección que da, como base, el propio haber en cuanto constituye la mejor prevención de las relaciones de dominación. No obstante la relación entre propiedad y opciones de libertad sea difícil de cuestionar, lo que sí requiere mayor fundamentación es que sea el Estado quien asegure la dotación mínima como un deber político. Claro está que los defensores del predominio de la libertad negativa no encontrarán argumentos válidos en la defensa del aseguramiento de una dotación mínima de capacidades y menos aún, por ejemplo, de una "renta mínima universal" o de una "renta básica ciudadana" incondicionalmente distribuida.

Es manifiesto, entonces, que desde el enfoque de las capacidades se juzga que, si bien tienen mayor importancia los derechos civiles y políticos, no es menos cierto que sin derechos económicos y sociales, muchas personas estarían privadas de ejercer los primeros: Ser "libre de" requiere de ser "libre para". Incluso Nussbaum argumenta, mostrando la incoherencia de la noción de "libertad negativa", que "todas las libertades son positivas" en tanto se trata de ejercer una actividad por parte de las personas. Esta acción, desde luego, depende de poner límite a la interferencia (Nussbaum, 2012: 87), pero, lo central es la capacidad para funcionar. Por ello, es bastante evidente que, tanto para la libertad negativa como para libertad positiva, los derechos sociales son fundamentales, puesto, que para la primera actúan como una suerte de "burbuja" de no interferencia" (Berisso, 2011: 20) y, para la segunda, como la base suficiente para "ser libre de florecer", en tanto, "el humano necesita estar mínimamente nutrido, razonablemente sano, cultivado en alguna medida" (Berisso, 2011: 20). En consecuencia, es innegable que las desigualdades y privaciones en el plano social y económico guardan relación con las desigualdades políticas.

La importancia que Nussbaum asigna a los derechos económicos y sociales, le lleva a redefinir la distinción entre los " derechos de primera generación' (políticos y civiles) y los ‘derechos de segunda generación' (los económicos y sociales)". La razón radica en que, al entender de Nussbaum, todos los derechos suponen las precondiciones sociales y económicas. En otras palabras, para la profesora neoyorquina "todos los derechos requieren de una acción positiva de los gobiernos (gasto público incluido) $\mathrm{y}$, por consiguiente, hasta cierto punto, todos son derechos económicos y 
sociales" (Nussbaum, 2012: 88). De estos juicios se desprende que toda ciudadanía, desde cierto respecto, es "social" y "económica". Luego, reiteramos que la importancia de los derechos sociales es basal en el sentido de asentar las condiciones del ejercicio universal de los derechos políticos. Difícilmente se puede tender al ideal de igualdad si no se acepta que "las condiciones de libertad deben ser las mismas para todos" (Nussbaum, 2014: 151).

\subsection{Dotación de capacidades frente a rentas de acceso universal}

Con todo, el enfoque de las capacidades de Nussbaum en su búsqueda de una justicia social en el marco del liberalismo político, no se centra en la renta universal básica o en el "ingreso básico de ciudadanía" (renta básica ciudadana), orientada a la "libertad para todos" en el sentido que le da Van Parijs. Primero, porque con la renta universal volvemos a hacer girar el problema de la justicia social en torno a las "cosas" — aunque algunos de estos bienes tengan el carácter de capacidades - al modo utilitario y no en las capacidades (Nussbaum, 2007: 151), segundo, porque no existe una permanente relación entre ingresos y bienestar, y, tercero, porque tiende a promover una idea de libertad en que las libertades no admiten jerarquización.

Respecto a esto último, cabe recordar que una de las críticas que Nussbaum le hace a Sen, es no definir una lista de capacidades, justamente, porque, al omitirla, se hace imposible distinguir los funcionamientos o libertades "malas" de las "buenas" conforme a la justicia social. Por ello, que, para la filósofa, "parece de suma y urgente importancia distinguir aquellos factores que son auténticamente fundamentales (como la libertad de expresión o la protección de la integridad física) de aquellos que no son o que, incluso, pueden resultar negativos" (Nussbaum, 2012: 95). Es más, como un proyecto político preocupado de la justicia social para todos $y$, por lo tanto, atento a lo que "todos podrían querer", el enfoque de las capacidades ha de priorizar algunas libertades. Dice la profesora de Chicago:

Todo proyecto político que se proponga proteger la igualdad de valor de ciertas libertades básicas para las personas pobres y mejorar las condiciones de vida de estas necesita proclamar con toda franqueza que algunas libertades tienen importancia central para efectos políticos y otras, claramente, no la tienen. (Nussbaum, 2012: 94)

Sin embargo, si bien Nussbaum discrepa con Van Parijs en la centralidad que da a algunos elementos, no difiere en la intención de avalar la 
necesidad del aseguramiento de los derechos sociales. Por tanto, no puede pensarse que Nussbaum, al disentir con el filósofo belga respecto a la centralidad del "ingreso básico incondicionado", esté negando la exigencia fundamental "de un mínimo existencial garantizado por el Estado" dado que son dos cosas distintas. Ocurre que mientras el mínimo existencial está orientado a las necesidades elementales, la renta básica está dirigida a la libertad y a la realización de los modos de vida de las personas. Mas, Nussbaum piensa que los gobiernos y las instituciones cuando pretenden, no solo aportar a la "seguridad social", sino lograr generar libertades sustanciales, en esa instancia cuentan más las capacidades que los ingresos.

El profesor belga al hacer la distinción entre "libertades formales" y "libertades reales", dando cuenta de la insuficiencia de la distinción entre libertad negativa y positiva al modo como la entiende Hayek y Buchanan, pone a disposición una forma de diferenciar el buen desarrollo humano del aparente, desde la perspectiva del ejercicio real de los derechos. A nuestro entender, esta categorización sirve para marcar, de un modo similar al de Nussbaum, la diferencia entre los derechos en cuanto escritos en el papel y los derechos que efectivamente pueden ejercer los ciudadanos, y, a su vez, nos permite dar cuenta del elemento económico-social que falta para ejercer una real ciudadanía política más allá de la propuesta del propio Van Parijs.

Utilizando la conceptualización del profesor de Lovaina, cabría distinguir una "ciudadanía política" meramente formal que implica "seguridad" y "propiedad de sí", pero, que carece de lo que él llama "oportunidad" (Van Parijs, 1996: 45) ${ }^{1}$. Supuesto esto, al extrapolar al enfoque de Nussbaum la idea de "oportunidad", parece ser adecuado afirmar que correspondería al aporte de los derechos sociales al desenvolvimiento humano y, por tanto, a ciertas capacidades específicas que no serían exclusivamente los ingresos como lo entiende Van Parijs.

Insistimos, en que, pese a estos posibles acercamientos conceptuales, la propuesta de la filósofa no se centraría en una renta universal básica o en una renta básica ciudadana, por constituir estas un simple medio subordinado al valor en sí del florecimiento. En cierto modo, la vida vivida conforme a la propia valoración desde el poder que confieren las capacidades, constituye, para Nussbaum, el verdadero signo del desarrollo humano y de la propiedad de sí. Es pertinente afirmar que el enfoque de las capacidades

1 "De manera precisa, se trata de una sociedad que satisface las tres condiciones siguientes: 1. Existe alguna estructura de derechos bien defendida (seguridad). 2. En esta estructura cada persona es propietaria de sí misma (propiedad de sì). 3. En esta estructura cada persona tiene la mayor oportunidad posible para hacer cualquier cosa que pudiera querer hacer (ordenación leximín de la oportunidad)". (Van Parijs, 1996: 45) 
conecta de forma más estrecha la igualdad de oportunidades con los resultados posibles de dicha igualdad en tanto promueve "poderes" para funcionar.

Un acercamiento como el anterior tan lleno de salvedades, podría parecer improcedente, pero, desde el mismo republicanismo no se descarta la posibilidad de complementar la idea de la renta universal de Van Parijs con el enfoque de las capacidades. Es el propio Philip Pettit quien lo pone de manifiesto cuando sostiene que el enfoque de capacidades da lugar a una forma de determinar la "medida suficiente" de la renta básica diseñada por Van Parijs. Expresa al respecto:

Un nivel suficiente de renta básica lo constituiría aquel que, quizás en combinación con otros arreglos institucionales —un sistema educativo, un sistema sanitario, un sistema de ayudas a particulares para costearles los gastos legales, etc.- asegurara que el beneficiario contará con los medios necesarios para desenvolverse en el seno de la sociedad local; los medios —en términos de Adam Smith - para vivir sin avergonzarse de uno mismo; los medios —en los de Rawls - para vivir en condiciones de autorrespeto. (Pettit, 2008: 133)

En el fondo, el enfoque de las capacidades puede servir de base para el enfoque de la "renta básica ciudadana" en el momento en que conecta la libertad con una dotación de capacidades abriendo posibilidades de elección a la vez que profundiza y enriquece los criterios de la misma.

\subsection{Ciudadanía sin barreras y desarrollo}

Se desprende de lo afirmado que, de acuerdo con el enfoque de Nussbaum, con déficit social y económico — que redunda en una mengua política-, y sin una idea de justicia compartida y refrendada a nivel constitucional, no se puede hablar de desarrollo. En otras palabras, si una nación carece de una dimensión cívica robusta, aunque posea un alto grado de crecimiento económico, permanece fuera del desarrollo, pues, con ello, cierra diversas oportunidades de expansión vital a las personas. Una sociedad que se precie de justa no puede bloquear el desarrollo humano y parte de ese desarrollo está sujeto a la inclusión de las personas en la ciudadanía plena. Es evidente que, al hablar de ciudadanía ligada al desarrollo, no nos referimos a la ciudadanía pasiva, sino a la activa, es decir, a la de aquel ciudadano que supera la dependencia generada por el binestarismo del Estado — dentro de las naciones que han gozado de él ciertamente-, en pro de la autonomía y, a su vez, asume que las condiciones que el orden legal 
le ofrece, ha de redundar en un compromiso de participación y en adhesión cívica.

En el fondo, cuando se afirma que "pertenecer a una comunidad justa parece esencial para sentirse ciudadano" (Cortina, 2009: 26), se está diciendo algo que, desde el enfoque de las capacidades, es equivalente a sostener que la pertenencia a una comunidad que ofrece posibilidades de desarrollo humano es esencial para sentirse ciudadano. Pero, nuevamente hemos de recordar el status moral de la ciudadanía, puesto de relieve por Cortina, que exige mantener altas cotas de participación y hábitos de civilidad que son, también, fuentes del desarrollo. En razón de esto, la ciudadanía depende de una formación que la lleve a ser una disposición permanente, es decir, ha de ser una condición fruto del cultivo. Por tanto, se trata de crear capacidades para diversos funcionamientos, para el despliegue libre en relación a los asuntos que nos conciernen a todos, que al constituirse en hábitos adquiridos previenen a las personas de mermar en sus propósitos y les salvan de conductas antojadizas. Y, por supuesto, esta educación ciudadana económica entraña "la autolimitación de nuestras aspiraciones de bienestar individual" (Ulrich, 2006: 51), ya sea por razones de justicia social, ya por razones de sustentabilidad ecológica, que son muestra de corresponsabilidad a nivel local y planetario.

Cuando Nussbaum se propone dar cuenta de los nuevos retos que entraña la formación del ciudadano en la enseñanza universitaria, es el instante en que de modo más explícito distingue la importancia de dicha condición para el desarrollo humano, incluso un tanto más que cuando se refiere al peso que tiene para el desarrollo humano de las mujeres pobres de Ahmedabad. Así, el "cómo debe ser" y "qué debe saber" un ciudadano formado, en buena medida, en base a un curriculum universitario nos permite advertir la aspiración contrafáctica del ejercicio ciudadano de toda persona.

Justamente, en su libro El cultivo de la bumanidad la filósofa norteamericana sostiene la necesidad de una ciudadanía que, haciéndose eco de su status moral, permita tomar decisiones de manera comprensiva con la diversidad, de modo circunspecto respecto de la historia, y empática en lo que a los problemas humanos se refiere. A su juicio, el ser humano ha de ser capaz de "funcionar como ciudadano no solo en regiones o grupos locales, sino también, y más importante, como ciudadanos de un mundo complejo e interconectado" (Nussbaum, 2001: 25). Al ejercicio ciudadano aparecen adscritas varias capacidades o destrezas de las cuales Nussbaum destaca tres: la primera, "el examen crítico de uno mismo y de las propias tradiciones", la segunda, "el verse a sí mismos no solo como ciudadanos pertenecientes a una región o grupo, sino también, y por sobre todo, como seres vinculados a los demás seres humanos por lazos de reconocimiento 
y mutua preocupación" y, la tercera, la "imaginación narrativa" (Nussbaum, 2001: 29-30). A esta última, se la puede entender como la capacidad de ser sensible respecto de la vivencia del otro y de estar llano a la comprensión, siempre crítica, de su biografía. En seguida, Nussbaum añade otras capacidades referidas al conocimiento, en especial al científico, que complementan esta "ciudadanía inteligente" (Nussbaum, 2001: 31).

Ahora bien, dentro de un enfoque centrado en la persona como es el de Nussbaum, es imposible pensar que estas capacidades, que son para el estudiante de la Universidad de Chicago una exigencia formativa que viene a componer una doctrina comprensiva, no se extiendan hasta llegar a ser un ideal regulativo al cual ha de aspirar, como dijimos, en diversos grados, toda persona. Agreguemos, además, que si esta "ciudadanía inteligente" de Nussbaum congrega tan valiosas cualidades, es, también, imposible llegar a pensar que alguien tienda al florecimiento, conforme a la "norma de especie", careciendo de ellas y, en razón de lo mismo, es inadmisible que sin dichas capacidades exista desarrollo humano.

A la anterior necesidad formativa en la ciudadanía, se suma la creciente apertura de las fronteras de la misma que, por los efectos que acarrea, significa casi tanto como decir inclusión en el desarrollo. Tal concepto no difiere de la visión de la CEPAL que ha quedado sintetizada en el documento del año 2000 titulado Equidad, desarrollo y ciudadanía. En parte por querer ver extendida la ciudadanía, el informe se muestra altamente coincidente con el enfoque de las capacidades, es decir, asigna un alto valor a su ejercicio, no sólo entendiéndolo como una actividad valiosa por sí misma para la vida de las personas, sino como un modo de asegurar la representatividad de los "afectados" por las decisiones políticas y como una forma de lograr la estabilidad necesaria para el desarrollo económico. Dice el documento:

El ejercicio de la ciudadanía es, además, no sólo un derecho en sí mismo, que contribuye al bienestar de las personas, sino también el medio más efectivo para garantizar que los objetivos sociales del desarrollo estén adecuadamente representados en las decisiones públicas. De esta manera, contribuye a la configuración de un marco social y político de estabilidad, que favorece el propio desarrollo económico. De hecho, la cohesión social y la estabilidad política son vistas cada vez más, en un mundo globalizado, como una fuente de competitividad internacional. (NU, CEPAL, 2000: 47)

Las "decisiones públicas" que surgen contando con el ejercicio de la deliberación de los ciudadanos afectados - que ejercen su status moral de ciudadanos económicos principalmente-, permite el control democrático del capitalismo. De esta forma, cabe revertir el tan nefasto proceso en que 
el mercado se vuelve dueño de la política y que Van Parijs ha descrito tan acertada y sintéticamente cuando dice: "en el pasado teníamos un capitalismo controlado por la democracia y hoy se tienen democracias controladas por el capitalismo" (Cubillos, Slachevsky \& Yañez, 2019: 90). El status moral de la ciudadanía económica supone un grado suficiente de empoderamiento ciudadano que permita asumir una corresponsabilidad respecto de la economía privada de las empresas. Esto debe darse a tal nivel, que el ciudadano ha de ser capaz de exigir a las empresas el cumplimiento de sus deberes, " $\mathrm{y}$-como bien dice Ulrich- si no sirve de nada es asunto de la mayoría ciudadana ilustrada obligarles a cumplir su obligación mediante los métodos democráticos y del Estado de derecho" (Ulrich, 2006: 50).

A la par de lo anterior, podemos abundar en el valor que asigna Nussbaum a la ciudadanía prestando atención a cómo insiste en promoverla para personas que viven en situación de "discapacidad" o están precarizadas en extremo.

En principio, debemos recalcar que Nussbaum considera que el desarrollo humano por ser una exigencia universal fundada en la dignidad, todos aquellos que se quedan con las situaciones más desventajosas en la lotería de la vida, que sufren verdaderos "accidentes de nacimiento", necesitan ser considerados por la justicia y, por lo mismo, han de sumarse al desarrollo. Esto exige incluir a aquellas personas que no están capacitadas, a causa de su situación de dependencia, para entablar relaciones de reciprocidad respecto de los bienes. Así, la inclusión de las personas que, junto con tener un abanico muy limitado de capacidades para desplegar opciones vitales, no pueden dar nada a cambio de los beneficios que reciben, es una tarea prioritaria del enfoque de las capacidades (Nussbaum, 2007: 22). En conformidad con ello, Nussbaum ve la necesidad de reconsiderar el significado de la cooperación social hasta dar razón de por qué es necesario no verla exclusivamente desde el prisma de la "ventaja mutua", sino desde la perspectiva de la solidaridad y la gratuidad (Nussbaum, 2007: 302). Por supuesto, esta perspectiva se asienta en el principio de reconocimiento mutuo, entendiendo éste como la obligatoriedad de extender mi autorreconocimiento como persona digna de respeto, a las demás personas que, como tales, han de tener o habrían de tener, legítimamente, mi misma pretensión (Ulrich, 2006).

Según queda establecido, para la filósofa, la posesión de la ciudadanía activa tiene un lugar tan relevante para el desarrollo humano que se empeña en buscar los modos en que las personas "con deficiencias y discapacidades" puedan ejercerla, pese a que estén muy lejos de responder equivalentemente, por ejemplo, a prestaciones distributivas. Con este fin, pretende que dichas personas participen en la elección de los principios políticos fundamentales por medio de una forma de tutela o curaduría que les 
permita ser sujetos primarios de justicia (Nussbaum, 2007: 147). Es decir, proyecta convertir en exigencia de justicia la implementación de las condiciones de participación política, de ejercicio ciudadano, sin dejar fuera a las personas con graves problemas cognitivos o similares (Nussbaum, 2007: 208) dado que deben participar en "elegir cómo vamos a vivir 'nosotros' en una sociedad política” (Nussbaum, 2007: 147). A lo que a esto se refiere, Donaldson y Kymlicka, detractores de Nussbaum en varios puntos, coinciden esta vez con ella en la necesidad de fomentar la ya nombrada "agencia política democrática", no obstante se la suponga para ciertas personas como una "actividad dependiente". Mas, la "dependencia" debe diferir de aquella custodia paternalista que, según Donaldson \& Kymlicka, defiende Nussbaum (Donaldson \& Kymlicka, 2018: 112).

De esta forma, se da cuenta del valor que tiene para el ser humano la actividad que deriva de la agencia política y, pese a que para muchos suele ser un "logro parcial y frágil", da cuenta del valor incondicionado que tiene la autodeterminación. Sin obstáculo, podrían llamarse ciudadanos a personas que sólo poseen nacionalidad y soberanía, mas, "sería una idea empobrecida de la ciudadanía" y de lo que implica, a su vez, el desarrollo humano (Donaldson \& Kymlicka, 2018: 110).

De entre las diez capacidades básicas propuestas por Nussbaum, que son exigencias de justicia social y cuya implementación es condición del desarrollo humano, se incluye el "control sobre el entorno propio" (Nussbaum, 2007: 393). Tal capacidad tiene un aspecto, por un lado, politico que corresponde al ejercicio de la "ciudadanía activa" y a «los derechos de participación política»y, por otro, uno material que "incluye ciertos tipos de protecciones de los derechos de la propiedad y del trabajo, incluido el derecho a sindicarse y libertad de elegir la ocupación que se desee" (Nussbaum, 2007: 393). Conforme a ello, es claro que, para Nussbaum, las capacidades para la deliberación ciudadana y la vida política, se cuentan entre las que son insustituibles "para una vida con dignidad humana" y, por lo mismo, "tenemos un motivo moral muy fuerte para promover su florecimiento y eliminar los obstáculos a su desarrollo" (Nussbaum, 2007: 343). La cooperación humana, incluso a riesgo y certeza de no ganar nada, no debe estar fundada en la benevolencia ni menos en la capacidad de establecer contratos, sino en el respeto de la dignidad humana. En otros términos, a la hora de establecer los principios normativos Nussbaum apelará al valor incondicionado de las personas, dice taxativamente: "los principios políticos del enfoque de las capacidades se apoyan en argumentos independientes basados en la dignidad humana" (Nussbaum, 2007: 102).

En definitiva, desde cierto prisma, carecer de ciudadanía es pobreza. Es decir, si bien la pobreza es la que suele trabar el ejercicio ciudadano, también hay que decir que no tener las capacidades para funcionar en la 
comunidad política viene a ser en sí misma una modalidad de dicha pobreza. Aún más, si algo representa lo contrario al desarrollo son las diversas clases de pobreza que supone el no poder funcionar para alcanzar un nivel de "vida satisfactoria". Justamente, Sen considera que la pobreza no es sólo la falta de ingresos, sino que, como se ha repetido desde siempre en los sectores cristianos, el concepto integra diversas formas de privación. Dice el economista:

Los bajos ingresos son, sin duda alguna, un factor importante, pero también los son la falta de escuelas, la ausencia de instalaciones sanitarias, la ausencia de medicamentos, la subordinación de la mujer, situaciones medioambientales peligrosas o falta de empleo (que afecta a algo más que los ingresos). (Sen, 2008: XV)

\section{CONCLUSIÓN}

Cuando se sistematizan los modelos de ciudadanía (comunitarista, republicano, comunicativo, etc.), por razones propedéuticas y pedagógicas, suelen quedar tan definidos en sus límites diferenciadores que, con facilidad, quedan fuera ciertas variantes de los mismos. En estos esquemas, el modelo liberal es, a nuestro entender, el que más sufre con esta mirada de didáctica unilateralidad y, por lo mismo, es al que más se le expone estando necesitado de correctivos exógenos o simplemente de ser superado. Por ello, la perspectiva liberal al ser caracterizada, por lo general, tan poco allegada a la democracia, a la justicia social y al ejercicio ciudadano, nos pondría difícil la tarea de buscar dónde caben viejos liberales como Hobhouse, Dewey, De Ruggiero, por nombrar algunos de los preclaros revisionistas. Pero, acontece que estas dificultades clasificatorias que excluyen de este modelo de ciudadanía a estos viejos "liberales sociales", también afecta a una moderna filósofa liberal como es Martha Nussbaum.

Nussbaum desde su liberalismo social entiende que el despliegue de la personalidad humana se colma en gran medida buscando sus intereses privados y participando en la sociedad civil, pero, a su entender, se completa cuando la persona se hace parte de la sociedad política. Acontece que el primado liberal de la libertad civil se equilibra, en el enfoque de Nussbaum, con la libertad política. En esta medida, la filósofa no sólo quiere ciudadanos en vez de súbditos o siervos, sino, especialmente, que el celo liberal por el respeto del fuero interno no se convierta en una máscara del egoísmo y de la falta de solidaridad.

A raíz de lo anterior, cuando el enfoque de las capacidades quiere deslindar, dentro de su teoría de la justicia, su idea del desarrollo bumano, el ejercicio ciudadano y los compromisos que involucra, se transforma en un 
elemento que le es inherente. Se hace evidente que lejos está Nussbaum, como también lo estuvieron los mencionados Hobhouse, Dewey, De Ruggiero, de pensar que el florecimiento humano sea sólo dependiente de la libertad de competencia, de la no interferencia en la iniciativa privada, o haciéndose independiente de la intromisión del Estado. Es palmario que la ciudadanía en su propuesta, que viene a ser la personalidad en su faz política y pública, no es un mero instrumento para la satisfacción del interés individual, sino un fin en sí misma en cuanto constituye una praxis, es decir, una actividad vital con un valor en sí. Qué duda cabe que sería impreciso defender que la filósofa llega a esta idea más por liberal que por aristotélica, pero, lo cierto es que hay antecedentes en el liberalismo que permiten concebir la actividad política como un aspecto que no constriñe las capacidades, sino que permite su manifestación. Es más, como liberal, y no sólo como aristotélica, Nussbaum defiende la necesidad de una cultura pública de las emociones destinada a preservar los principios políticos consensuados, es decir, existe una responsabilidad formativa de la sociedad respecto de la política. Debe haber, al entender de Nussbaum, una "cultura política comprometida" con ciertos valores y hábitos que se asienten en el respeto a la dignidad humana. Al considerar estos aspectos, es impensable que el desarrollo sea realizable sin una ciudadanía que sea susceptible de universalización, tanto como sería imposible concebirlo en una sociedad carente de justicia.

Hemos establecido, entonces, que el liberalismo político de Nussbaum admite que hay aspectos que no estando vinculados necesariamente con el crecimiento económico, son centrales para el desarrollo. Uno de estos aspectos es la adquisición de la ciudadanía en sus diversas tipologías, dado que según considera Nussbaum, las distintas ciudadanías vienen a ser inherentes al desarrollo en la medida que aportan a la capacidad de ser y hacer de las personas. La ciudadanía se vincula con la posesión y el reconocimiento de ciertas capacidades que permiten el goce de ciertos derechos y el cumplimiento de determinadas obligaciones (Martínez, 2007).

Conjuntamente, hemos hecho patente que la ciudadanía social configura las precondiciones de cualquier proyecto de vida y suma garantías a las obtenidas gracias a los bienes que suelen ser distribuidos, por ciertos estados, a las personas por el sólo hecho de reconocer su dignidad. En este sentido, se puede afirmar que los diversos aspectos que se proponen como requerimientos para la "igualdad básica" y que configuran la concepción de justicia social del enfoque de las capacidades, se conectan con el desarrollo humano. Por ello, desde el enfoque de las capacidades no se puede dar por buena una teoría de la justicia que desconozca las condiciones básicas económicas y sociales para el desarrollo como exigencia universal. 
Del mismo modo, no cabe entender que el desarrollo ignore el aseguramiento de los aspectos económicos y sociales de la ciudadanía como condición del goce de los aspectos políticos. En razón de lo anterior, son tan necesarias las "políticas estatales positivas" que hagan posible una real ciudadanía social que inmunice a las personas de las relaciones de dominación, de las interferencias en el uso de su libertad, del tener que "renunciar a sus derechos por desesperación" financiera y de tantos otros males que surgen de la falta de autonomía económica (Nussbaum, 2012: 87).

Junto a lo anterior, hay que afirmar que, a estas alturas de la reflexión en torno al desarrollo humano y de los pueblos, no llama la atención que sea posible desvincular el crecimiento económico del desarrollo, pues, basta con hacer referencia a algunos países en los que dicho crecimiento económico ha acarreado desigualdades reñidas con la dignidad de las personas. Ocurre que son muchos los países que pese a tener un PIB alto, la mayor parte de las personas carece de seguridad sanitaria o bien no tienen nada que decir respecto de las medidas económicas que les afectan. Es evidente, que hay un crecimiento económico que generando la prosperidad de una minoría, es enemigo de la vida buena de la mayoría de las personas y, por lo mismo, se le considera contrario al desarrollo. Sin embargo, desde hace un tiempo se viene remarcando un aspecto que sí sorprende, sobre todo a aquellos que se mueven por una lógica utilitaria, a saber: el crecimiento económico muchas veces no sólo debe ser acotado, sino francamente rechazado. En específico, hay que decir que el enfoque de las capacidades considera, sin ser antiproductivista, que las estrategias de crecimiento económico han de ser impugnadas toda vez que no sean condición del florecimiento de las personas. El enfoque de las capacidades de Nussbaum entiende que el cese momentáneo del crecimiento económico, no necesariamente pone en peligro la ciudadanía social ni menos la misma ciudadanía económica, pues, la posibilidad de que puedan imperar criterios no productivistas pende, en parte, del empoderamiento ciudadano que puede defender la prevalencia de otros criterios no económicos.

Finalmente, dejamos establecido que la ciudadanía es una parte integrante y no opcional de la prosperidad y el desarrollo de los pueblos. De hecho, si nos preguntamos por las razones de la revuelta social que ha vivido recientemente Chile, y otros países de Latinoamérica, se podrán encontrar en buena parte unidas al descuido, al nivel legislativo y gubernamental, de la ciudadanía económica. Esta viene a ser un tipo de ciudadanía, que siendo en parte arquitectónica respecto de la ciudadanía social, no se ha contemplado lo suficientemente en el Estado de derecho chileno y, por tanto, ha buscado su debido reconocimiento. En efecto, el incremento de la autoconciencia y el aumento concomitante de las aspiraciones de las personas, no solo de bienes sociales, sino de autonomía respecto a los 
asuntos económicos que les afectan, por no tener un encauce institucional, ha tomado la forma de la protesta callejera y de una violencia inusitada.

\section{REFERENCIAS}

Benhabib, S. (2005). Los derechos de los otros. Extranjeros, residentes y ciudadanos. Barcelona: Gedisa.

Berisso, L. (2011). Presentación. En L. Berisso (Comp.), C. Demárquez, N. Villarreal, y K. Wild. Introducción a la Renta Básica Universal (pp. 9-22). Montevideo: Departamento de Publicaciones, Unidad de Comunicaciones de la Universidad de la República (UCUR).

Brubaker, R. (1992). Citizenship and Nationhood in France and Germany. Cambridge: Harvard U.P.

Conill, J. (2001). Ciudadanía económica en la jungla global. En A. Cortina y J. Conill (Eds.), Educar en la ciudadanía (pp. 245-265). Valencia: Institució Alfons el Magnànim.

Cortina, A. (2001). El protagonismo de los ciudadanos. Dimensiones de la ciudadanía. En A. Cortina y J. Conill (Ed.), Educar en la ciudadanía (pp. 13-30). Valencia: Institució Alfons el Magnànim.

Cortina, A. (2002). Por una ética del consumo. La ciudadanía del consumidor en un mundo global. Madrid: Taurus.

Cortina, A. (2009) Ciudadanos del mundo. Hacia una teoría de la ciudadanía. Madrid: Alianza Editorial.

Crocker, D. (2003). Globalización y desarrollo humano: aproximaciones éticas. En J. Conill y D. Crocker (Eds.), Republicanismo y educación cívica, ¿Más allá del liberalismo? (pp. 75-98), Granada: Comares.

Cubillos, P., Slachevsky, N. \& Yáñez, R. (2019). El Estado Social de mañana: diálogos sobre bienestar, democracia y capitalismo con Göran Therborn, Philippe V an Parijs y Nicolas Duvoux. Santiago de Chile: LOM.

Donaldson, S. \& Kymlicka, W. (2018). Zoópolis, una revolución animalista. Madrid: Errata Naturae.

Ferrajoli, L. (2001). De los derechos del ciudadano a los derechos de la persona. En L. Ferrajoli. Derechos y garantías. La ley del más débil (pp. 97-123). Madrid: Trotta.

Goldin, I. (2016) La búsqueda del desarrollo. El crecimiento económico, los cambios sociales y algunas ideas. Zaragoza: Tell Editorial.

Goulet, D. (1999). Ética del desarrollo. Guía teórica y práctica. Madrid: IEPALA.

Held, D. (1997). La democracia y el orden global. Del Estado moderno al gobierno cosmopolita. Barcelona: Paidós.

Jongitud, J. (2017). Controlar el capital y redimensionar el derecho de propiedad: propuestas para la ética del desarrollo. Veritas, (37), 51-77.

Martínez, E. (2000). Ética para el Desarrollo de los pueblos. Madrid: Trotta.

Martínez, E. (2007). Desarrollo como plena ciudadanía. En J. Jongitud (Comp.), Ética del desarrollo y responsabilidad social en el contexto global (pp. 139-169). Veracruz: Biblioteca Veracruzana. 
Martínez, P. (2015). El “enfoque de las capacidades" de Martha Nussbaum frente al problema de la ética animal. Veritas, (33), 71-87.

Nussbaum, M. (2001). El cultivo de la humanidad. Una defensa clásica de la reforma en la educación liberal. Barcelona: Editorial Andrés Bello.

Nussbaum, M. (2007). Las fronteras de la justicia. Consideraciones sobre la exclusión. Barcelona: Paidós.

Nussbaum, M. (2010). Sin fines de lucro. Por qué la democracia necesita de las humanidades. Buenos Aires: Katz.

Nussbaum, M. (2012). Crear capacidades. Propuesta para el desarrollo bumano. Barcelona: Paidós.

Nussbaum, M. (2014). Emociones políticas. ¿Por qué el amor es importante para la justicia? Barcelona: Paidós.

Pettit, Ph. (2008). ¿Un derecho republicano a la Renta Básica? Sin Permiso, (4), 132-144.

Sen, A. (2000). Desarrollo como libertad. Barcelona: Planeta.

Sen, A. (2006). El valor de la democracia. Madrid: Viejo Topo.

Sen, A. (2008). Prólogo. En D. Green. De la pobreza al poder. Cómo puede cambiar el mundo ciudadanos activos y Estados eficaces (pp. XV-XVIII). Barcelona: Intermón Oxfam.

Sen, A. (2010). La idea de la justicia. Madrid: Taurus.

Sunstein, C. (2018). Las cuentas pendientes del sueño americano. Por qué los derechos sociales y económicos son más necesarios que nunca. Buenos Aires: Siglo XXI Editores.

Ulrich, P. (2006). Ética mundial y economía mundial. Una perspectiva ética-económica. En H. Küng y K-J. Kuschel (Eds.). Ciencia y ética mundial (pp. 33-51). Madrid: Trotta.

Ulrich, P. (2008). Ética económica integrativa. Fundamentos de una economía al servicio de la vida. Quito: Abya-Yala.

Van Parijs, Ph. (1996). Libertad real para todos. Qué puede justificar el capitalismo (si hay algo que pueda hacerlo). Barcelona: Paidós. 